\title{
Alpha-I antitrypsin Pi*SZ genotype: estimated prevalence and number of SZ subjects worldwide
}

\author{
This article was published in the following Dove Press journal: \\ International Journal of COPD \\ 8 June 2017 \\ Number of times this article has been viewed
}

\author{
Ignacio Blanco' \\ Patricia Bueno ${ }^{2}$ \\ Isidro Diego 3 \\ Sergio Pérez-Holanda ${ }^{4}$ \\ Beatriz Lara ${ }^{5}$ \\ Francisco Casas- \\ Maldonado ${ }^{6}$ \\ Cristina Esquinas ${ }^{7}$ \\ Marc Miravitlles 7,8
}

'Alpha I-Antitrypsin Deficiency Spanish Registry (REDAAT), Lung Foundation Breathe, Spanish Society of Pneumology (SEPAR), Barcelona, Spain; ${ }^{2}$ Internal Medicine Department, County Hospital of Jarrio, Principality of Asturias, Spain; ${ }^{3}$ Materials and Energy Department, School of Mining Engineering, Oviedo University, Principality of Asturias, Spain; ${ }^{4}$ Surgical Department, University Central Hospital of Asturias, Oviedo, Spain; ${ }^{5}$ Respiratory Medicine Department, Coventry and Warwickshire University Hospital, Coventry, UK; ${ }^{6}$ Pneumology Department, University Hospital San Cecilio, Granada, Spain; ${ }^{7}$ Pneumology Department, Hospital Universitari Vall d'Hebron, Barcelona, Spain; ${ }^{8} \mathrm{CIBER}$ de Enfermedades Respiratorias (CIBERES), Barcelona, Spain
Correspondence: Marc Miravitlles Pneumology Department, Hospital Universitari Vall d'Hebron,

Passeig de la Vall d'Hebron I19-129,

08035 Barcelona, Spain

Tel +34932746I07

Email mmiravitlles@vhebron.net
Abstract: The alpha-1 antitrypsin (AAT) haplotype $\mathrm{Pi}$ *S, when inherited along with the $\mathrm{Pi}^{*} \mathrm{Z}$ haplotype to form a $\mathrm{Pi}$ *SZ genotype, can be associated with pulmonary emphysema in regular smokers, and less frequently with liver disease, panniculitis, and systemic vasculitis in a small percentage of people, but this connection is less well established. Since the detection of cases can allow the application of preventive measures in patients and relatives with this congenital disorder, the objective of this study was to update the prevalence of the SZ genotype to achieve accurate estimates of the number of $\mathrm{Pi}^{*} \mathrm{SZ}$ subjects worldwide, based on studies performed according to the following criteria: 1) samples representative of the general population, 2) AAT phenotyping characterized by adequate methods, and 3) selection of studies with reliable results assessed with a coefficient of variation calculated from the sample size and $95 \%$ confidence intervals. Studies fulfilling these criteria were used to develop tables and maps with an inverse distance-weighted (IDW) interpolation method, to provide numerical and geographical information of the $\mathrm{Pi}$ * $\mathrm{SZ}$ distribution worldwide. A total of 262 cohorts from 71 countries were included in the analysis. With the data provided by these cohorts, a total of $1,490,816 \mathrm{Pi}^{*} \mathrm{SZ}$ were estimated: 708,792 in Europe; 582,984 in America and Caribbean; 85,925 in Africa; 77,940 in Asia; and 35,176 in Australia and New Zealand. Remarkably, the IDW interpolation maps predicted the $\mathrm{Pi}^{*} \mathrm{SZ}$ prevalence throughout the entire world even in areas lacking real data. These results may be useful to plan strategies for future research, diagnosis, and management of affected individuals.

Keywords: SERPINA1, alpha-1 antitrypsin deficiency, protease inhibitor, genetic epidemiology, SZ genotype, inverse distance-weighted interpolation, geographic information system

\section{Introduction}

Human alpha-1 antitrypsin (AAT) is a 52-kDa glycoprotein mainly secreted by hepatocytes. Its main physiological function is to protect the matrix proteins of the lungs (especially elastin) from the proteolytic effects of proteases (especially neutrophil elastase and proteinase 3 ) released by activated and dying neutrophils and serine proteases released by invading bacteria. ${ }^{1}$

Human AAT is codified by the SERPINA1 gene, located at the distal end of the long arm (q) of the fourteenth chromosome at position q31-32.3. This gene is organized into three noncoding exons (1A, 1B, and 1C), four coding exons (II-V), and six introns. ${ }^{2}$ The AAT gene has two alleles that are transmitted by recessive autosomal codominant Mendelian inheritance. ${ }^{3}$ SERPINA1 alleles are named with the prefix $\mathrm{Pi}^{*}$ (protease inhibitor*). ${ }^{4}$ Normal alleles are designated $\mathrm{Pi}^{*} \mathrm{M}$, and the most prevalent deficiency alleles are $\mathrm{Pi}^{*} \mathrm{~S}$ and $\mathrm{Pi}$ Z Z, or simply S and Z. Mutated S (Glu264Val) and Z (Glu342Lys) alleles produce proteins with conformational changes that polymerize in the rough endoplasmic reticulum of the producing cells, forming stable polymers that are retained within hepatocytes without being secreted into the bloodstream and 
secondarily causing a decreased concentration of AAT in blood and tissues. ${ }^{5}$ The vast majority of genotypes found in clinical practice are combinations of $\mathrm{M}, \mathrm{S}$, and $\mathrm{Z}$ alleles, that is, $\mathrm{Pi} * \mathrm{MM}$ (normal genotype present in $\sim 85 \%-95 \%$ of people, expressing $100 \%$ of serum AAT), $\mathrm{Pi}^{*} \mathrm{MS}, \mathrm{Pi}^{*} \mathrm{SS}$, $\mathrm{Pi}^{*} \mathrm{MZ}, \mathrm{Pi}^{*} \mathrm{SZ}$, and $\mathrm{Pi}$ ZZZ (five deficiency genotypes present in almost the remaining $5 \%-15 \%$ of the population, expressing $\sim 80 \%, 60 \%, 55 \%, 40 \%$, and $15 \%$ of AAT, respectively). ${ }^{6}$

Severe alpha- 1 antitrypsin deficiency (AATD) has been defined by serum AAT levels $<11 \mu \mathrm{M} / \mathrm{L}$ (measured by the purified standard used in the U.S. Registry) or $<57 \mathrm{mg} / \mathrm{dL}$ measured by a commercial standard nephelometry (to convert micromolar to milligrams per deciliter you must multiply by a conversion factor of 5.2). ${ }^{7}$ This hereditary condition is characterized by an increased risk for chronic obstructive pulmonary disease (COPD) (ie, lung emphysema, persistent airflow obstruction, and/or chronic bronchitis) in adults; liver disease (ie, cholestasis, cirrhosis, and hepatocarcinoma) in children and adults; and much less frequently systemic vasculitis and neutrophilic panniculitis. ${ }^{7}$ In clinical practice, $96 \%$ of pathologies associated with AATD occur in homozygous ZZ, and the remaining $4 \%$ in heterozygous SZ and the extremely infrequent "rare" and "null" genotypes. ${ }^{8}$

The mean and 5th-95th percentile of AAT serum levels expressed by the SZ genotypes are $16(10-23) \mu \mathrm{M} / \mathrm{L}^{9}$ which are equivalent to $83(52-120) \mathrm{mg} / \mathrm{dL}$. These mean serum levels of $16 \mu \mathrm{M} / \mathrm{L}$ are considered sufficient to protect the lungs from proteases; however, there is a $20 \%$ of $\mathrm{Pi}^{*} \mathrm{SZ}$ individuals with AAT serum levels $<11 \mu \mathrm{M} / \mathrm{L}$ protective threshold who are at risk for AATD-related diseases. ${ }^{7}$ In fact, aggregating data from six studies demonstrated that the odds ratio (OR) for COPD in $\mathrm{Pi}$ *SZ compound heterozygotes compared with normal $\mathrm{Pi}$ MM individuals was significantly increased at 3.26 (95\% CI 1.24-8.57), these results showing that the $\mathrm{Pi}$ *SZ genotype is a significant risk factor for COPD. ${ }^{10}$ Other studies have found that smoking entails a major risk for the development of COPD, but in the absence of smoking the risk of developing COPD by a $\mathrm{Pi}{ }^{*} \mathrm{SZ}$ is negligible. ${ }^{11}$ Although no studies have been done to assess the effects of occupational and environmental pollutants on individuals with the SZ genotype, the ATS/ERS experts seem reasonable to assume that they can be as vulnerable as individuals with the $\mathrm{Pi}{ }^{*} \mathrm{ZZ}$ type. ${ }^{6}$

The causal relationship of the SZ genotype with other pathologies other than lung emphysema is much more debatable. $^{7}$
Because the incidence of SZ heterozygosity is so much higher than that of ZZ homozygosity, SZ heterozygosity may be an important public health problem, since the SZ genotype may favor the development of AATD-related diseases (especially COPD in smokers). Therefore, the objective of the present study was to update the epidemiological data about the prevalence and number of $\mathrm{Pi}^{*} \mathrm{SZ}$ genotypes, by means of detailed tables and IDW interpolation maps to provide the scientific community with up-to-date reliable information of the $\mathrm{Pi}$ SSZ distribution worldwide.

\section{Methods}

The methodology used in the present study was practically the same as that used by the authors for a recently published paper on genetic epidemiology of the AAT-Pi*Z allele/ genotype $^{12}$ (the list of sources are available from the authors upon request).

\section{Sources of the control cohort data used in the present study}

The present study used the available data from epidemiological studies performed to determine the frequencies of deficiency allele combinations for $\mathrm{PI}^{*} \mathrm{~S}$ and $\mathrm{PI}{ }^{*} \mathrm{Z}$, in the healthy control cohorts of individual case studies worldwide. The manuscripts were obtained through a variety of sources, including searches of the peer-reviewed literature from 1965 up to March 2017 on PubMed, Web of Science, Embase, and Google Scholar databases. Additional relevant studies were obtained by searching the bibliographies of the articles retrieved. ${ }^{12-23}$

\section{Study selection criteria}

The criteria for selection and exclusion of studies for analysis were: 1) Samples representative of the general population; 2) AAT phenotyping characterized by adequate methods, including isoelectric focusing (IEF), or, alternatively, crossed antigen-antibody electrophoresis or PCR; and 3) A coefficient of variation $(\mathrm{CV})$ of the $\mathrm{Pi}^{*} \mathrm{~S}$ and $\mathrm{Pi}^{*} \mathrm{Z}$ frequencies in each cohort to measure the precision of the results in terms of dispersion of the data around the mean. The value of this variable was adjusted for each country, according to the methodology used in several previous peer-reviewed publications by our group. The following studies were excluded from the analysis: 1) Cohort studies of patients with AATD-related diseases (eg, COPD, liver cirrhosis, rheumatoid arthritis, arterial dissections, etc.); 2) Screening studies in which phenotypes were determined only in samples with AAT concentrations below any given cut-off point. ${ }^{12}$ 


\section{Calculation of Pi allelic frequency and genotypic prevalence}

Gene frequency is defined as the frequency of all genes of a particular type, whether occurring in homozygotes or heterozygotes. The total number of alleles is twice the number of subjects. Therefore, the gene frequency was obtained by adding the number of $\mathrm{S}$ or $\mathrm{Z}$ alleles and expressing this total as a fraction of the total number of $\mathrm{Pi}$ alleles in the population (alleles per 1,000 genes of all Pi types).

The prevalence of the SZ genotype was calculated assuming the population to be in Hardy-Weinberg equilibrium: $p^{2}+2 p q+q^{2}=1$ (where $p$ is the proportion of the $\mathrm{Z}$ allele and $q$ is the proportion of the $\mathrm{S}$ allele).

In addition, 95\% confidence intervals (95\% CI) were calculated for allele frequencies, prevalence, and numbers of $\mathrm{Pi} * \mathrm{SZ}$.

\section{Inverse distance-weighting (IDW) multivariate interpolation maps}

$\mathrm{Pi}^{*} \mathrm{SZ}$ prevalence was used to develop maps using a geographic information system (GIS) of an inverse distanceweighted (IDW) interpolation method. IDW interpolation is based on the assumption that the attributed value of an unsampled point is the weighted average of known values within the neighborhood, and the weights are inversely related to the distances between the prediction location and the locations sampled. ${ }^{24}$ With this approach, maps show quantitative diverging data (starting from zero or a reference value) displayed by two contrasting brightness red-blue ramps, with the darker colors at each end representing "the more positive" (red) and "the more negative" (blue). ${ }^{23}$ According to this concept, in this study, Pi*SZ prevalence was represented by scales of 10 colors (with the range of reds representing the highest prevalence; the range of yellow and green colors depicting intermediate prevalences; and blues representing the lowest prevalence). Since the different colors correspond to numerical values, they can easily be converted into quantitative data with the naked eye.

\section{Results}

\section{Selected cohorts and the number of subjects studied}

A total of 262 cohorts ( 90 from Europe, 40 from America and Caribbean islands, 17 from Africa, 106 from Asia, 8 from Australia, and 1 from New Zealand) were selected. The CIA database comprised 71 of the 193 countries existing in the world. These cohorts included a total of 205,273 subjects, distributed as follows: 79,118 in America and Caribbean; 75,603 in Europe; 38,682 in Asia; 5,031 in Africa; 5,536 in Australia, and 1,303 in New Zealand.

\section{Prevalence and the number of $\mathrm{Pi}$ *SZ genotypes}

Tables 1-5 show the population of each country and the corresponding $\mathrm{Pi} * \mathrm{~S}$ and $\mathrm{Pi}^{*} \mathrm{Z}$ frequencies (expressed per 1,000, with 95\% CI) extracted from the selected studies. These basic data were used to calculate the SZ prevalence (with the Hardy-Weinberg formula) and the number of SZ (with 95\% CI) in each of the selected countries.

\section{Europe}

In Europe (Table 1), the mean SZ prevalence by regions (from the highest to the lowest) was as follows: Southern Europe, $1 \mathrm{SZ}$ per 483 subjects (1:483); Western Europe, 1:581; Northern Europe, 1:1,492; Central Europe, 1:1,712; and Eastern Europe, 1:11,818.

The mean SZ prevalence by countries (from the highest to the lowest) was as follows: Portugal, 1:205; Spain, 1:278; Latvia, 1:354; France, 1:413; Republic of Ireland, 1:424; Belgium, 1:551; the Netherlands, 1:617; UK, 1:900; and it was over 1 per 1,000 in the rest of European countries, reaching the minimum prevalence of almost 1:25,000 in Russia.

Consistent with the prevalence and number of inhabitants, the total number of SZ in Europe was 708,792 and their distribution by regions (from highest to lowest) was as follows: Western Europe, 295,187; Southern Europe, 291,856; Central Europe, 86,544; Northern Europe, 27,815; and Eastern Europe, 7,389.

By individual countries, the highest numbers were found in Spain (ie, 174,822), followed by France $(161,680)$, UK $(73,973)$, Italy $(64,137)$, Germany $(60,396)$, and Portugal $(52,836)$. The SZ numbers in the other countries were very variable, but always much lower than the above mentioned.

\section{America and Caribbean}

In America (Table 2), the highest prevalence was found in Canada with $1 \mathrm{SZ}$ per 907 subjects (1:907) and the USA $(1: 1,018)$. SZ prevalence was twice lower in Central and South America and Caribbean Islands, with an approximate mean value of $\sim 1: 2,000$.

In concordance with the prevalence and number of inhabitants of each country, the total number of SZ was 582,984, 


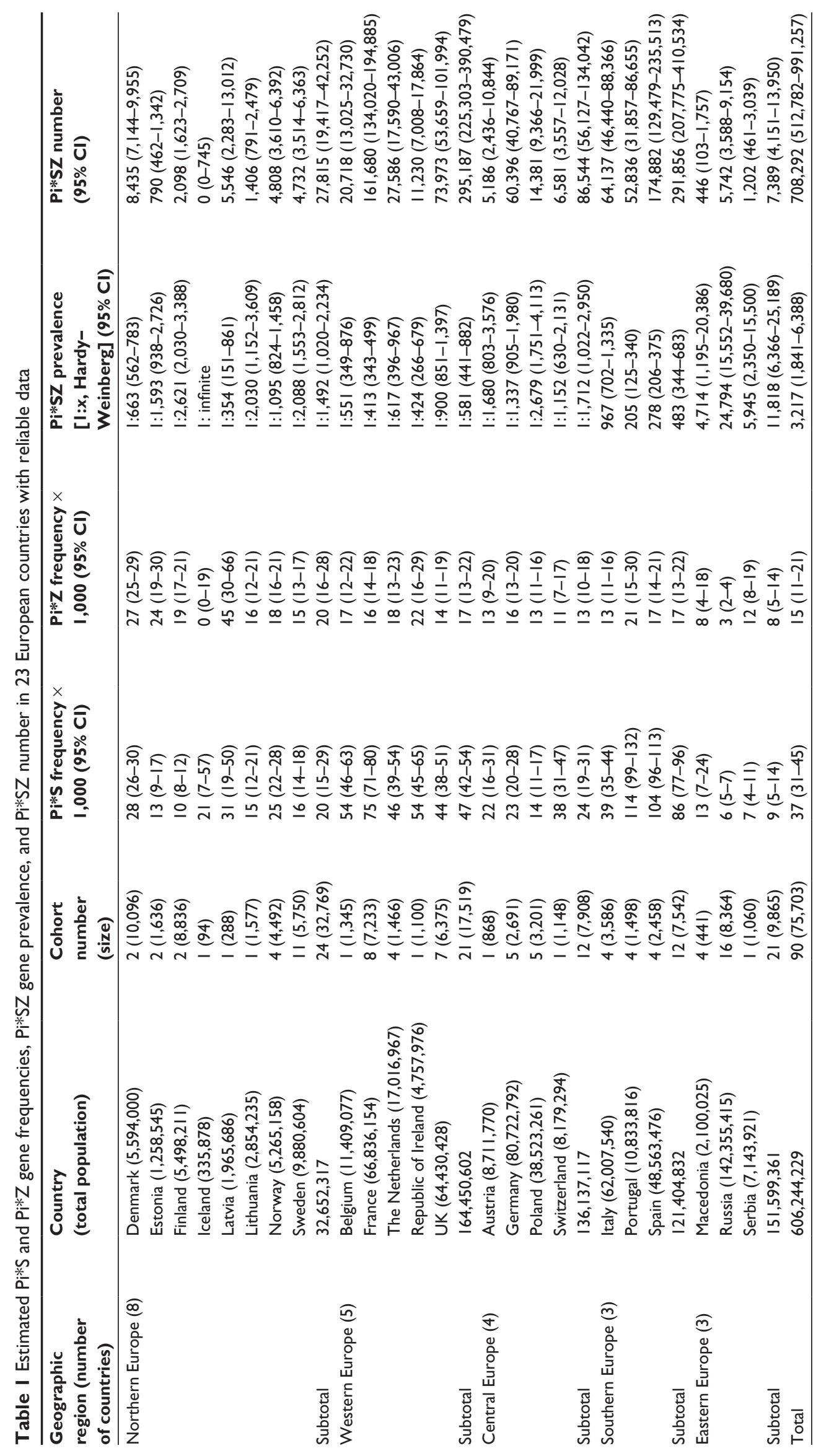




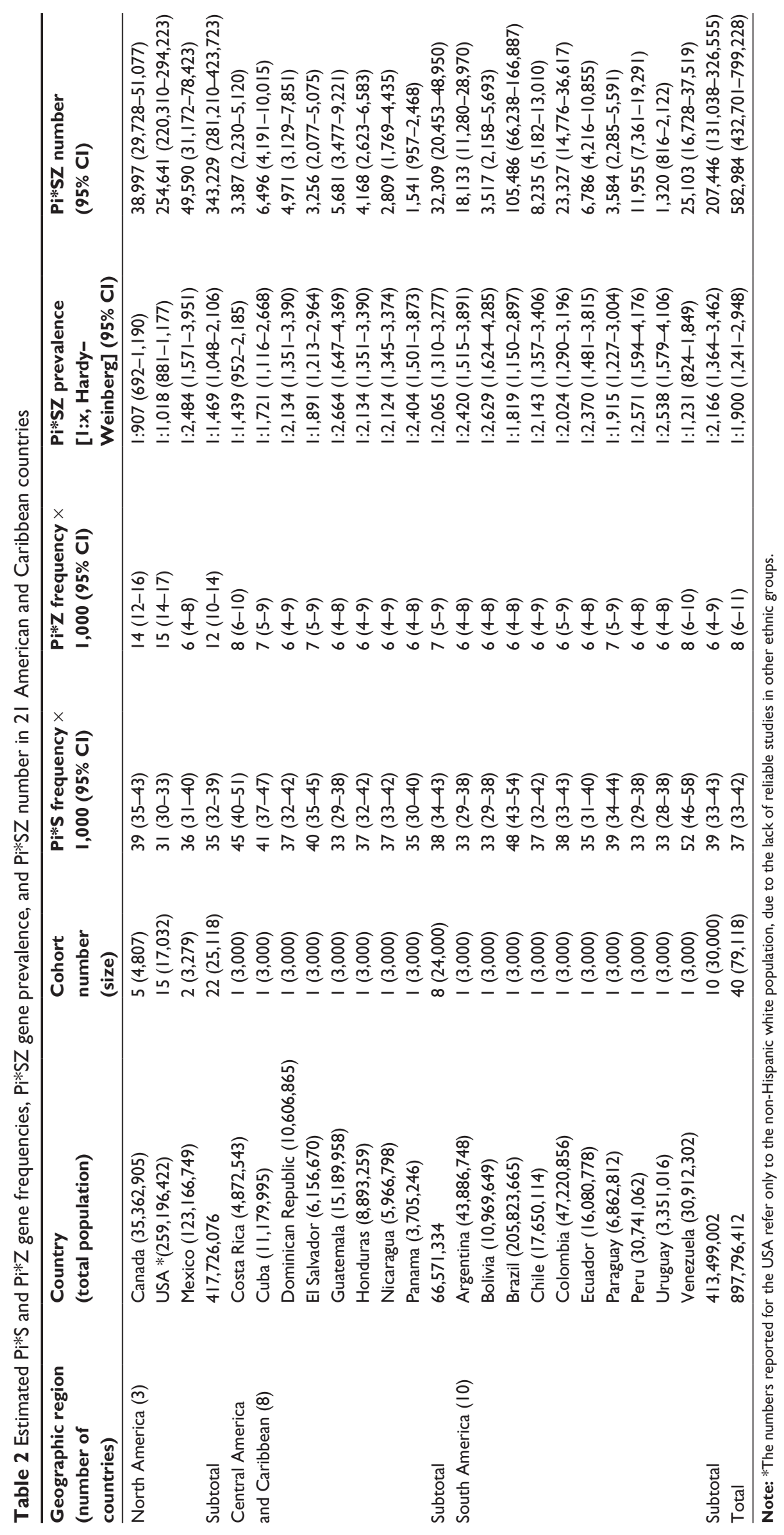




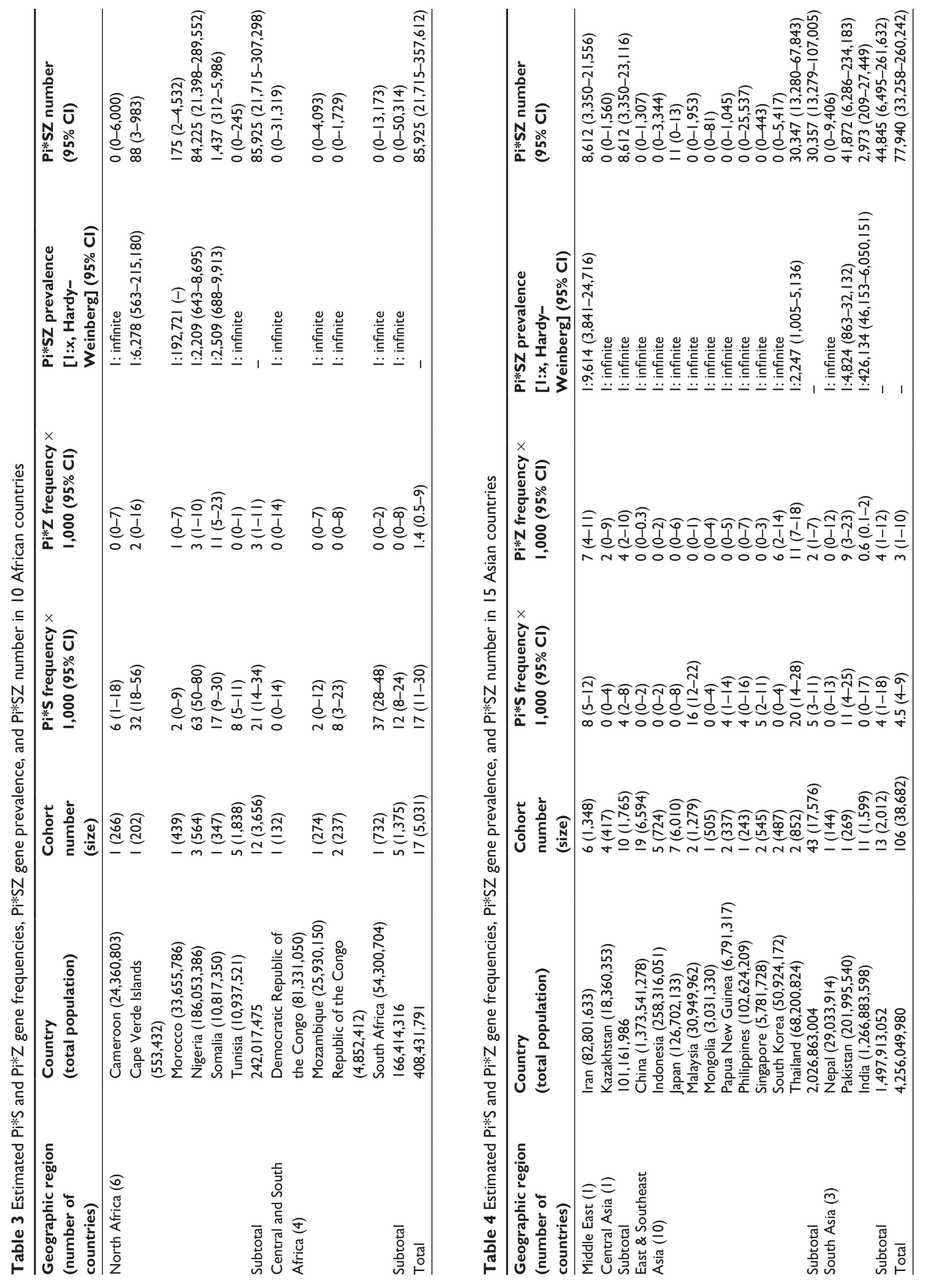


Table 5 Estimated Pi*S and Pi*Z gene frequencies, Pi*SZ gene prevalence, and Pi*SZ number in Australia and New Zealand

\begin{tabular}{|c|c|c|c|c|c|c|}
\hline $\begin{array}{l}\text { Geographic } \\
\text { region (number } \\
\text { of countries) }\end{array}$ & $\begin{array}{l}\text { Country } \\
\text { (total population) }\end{array}$ & $\begin{array}{l}\text { Cohort } \\
\text { number } \\
\text { (size) }\end{array}$ & $\begin{array}{l}\text { Pi*S frequency } \times \\
\mathrm{I}, 000(95 \% \mathrm{CI})\end{array}$ & $\begin{array}{l}\text { Pi*Z frequency } \times \\
\mathrm{I}, 000(95 \% \mathrm{CI})\end{array}$ & $\begin{array}{l}\text { Pi*SZ prevalence } \\
{[\mathrm{I}: x, \text { Hardy- }} \\
\text { Weinberg }](95 \% \mathrm{CI})\end{array}$ & $\begin{array}{l}\text { Pi*SZ number } \\
(95 \% \mathrm{Cl})\end{array}$ \\
\hline Australia and & Australia $(22,992,654)$ & $8(5,536)$ & $44(4 I-48)$ & $13(11-16)$ & I:840 (656-I,077) & $27,380(21,349-35,068)$ \\
\hline New Zealand (2) & New Zealand $(4,474,549)$ & I $(I, 303)$ & $39(32-47)$ & $22(17-29)$ & I:574 (365-909) & $7,796(4,920-12,275)$ \\
\hline Total & $27,467,203$ & $9(6,839)$ & $4 \mid(37-47)$ & $17(14-22)$ & I:707 (5।0-993) & $35,176(26,269-47,343)$ \\
\hline
\end{tabular}

Abbreviation: $\mathrm{Cl}$, confidential interval.

and the estimated number for geographic regions (from highest to lowest) was as follows: North America; 343,229; South America; 207,446; Central America and Caribbean, 32,309.

By individual countries, the highest numbers were found in the non-Hispanic white population from USA (ie, 254,641), followed by Brazil $(105,486)$, Mexico $(49,590)$, Canada $(38,997)$, Venezuela $(25,103)$, Colombia $(23,327)$, and Argentina $(18,133)$. In the remaining countries, the numbers were very variable, but always much lower than the above mentioned.

\section{Africa}

In Africa (Table 3), the highest prevalence was in Nigeria with $1 \mathrm{SZ}$ per 2,209 subjects $(1: 2,209)$ and Somalia $(1: 2,509)$. Prevalence was three times lower in Cape Verde Islands. In the rest of African countries, the prevalence was so low that it was practically unmeasurable.

In concordance with the prevalence and the number of inhabitants of each country, the total number of SZ was 85,$925 ; 98 \%$ of them in Nigeria; 1,437 in Somalia; 175 in Morocco, and 88 in Cape Verde. Remarkably, in most African countries, no SZ genotypes were found.

\section{Asia}

In Asia (Table 4), the highest prevalence was found in Thailand with $1 \mathrm{SZ}$ per 1:2,247 subjects $(1: 2,247)$, followed by Pakistan $(1: 4,824)$ and Iran $(1: 9,614)$. In the remaining countries, the SZ prevalence was so low that it was practically unmeasurable.

In concordance with the prevalence and number of inhabitants of each country, the total number of SZ was 77,940 (most of them in Pakistan and Thailand). Remarkably, in the vast majority of Asian countries, there were no SZ genotypes.

\section{Australia and New Zealand}

In Australia and New Zealand (Table 5), the SZ prevalence was 1:840 and 1:574, respectively, both values being very similar to those found in the Republic of Ireland and UK.
In concordance with the prevalence and number of inhabitants, the calculated total number of SZ was 35,176 (27,380 in Australia and 7,796 in New Zealand).

\section{IDW interpolation maps of Pi*SZ prevalence}

\section{Europe}

Figure 1 shows an IDW interpolation map, with the $\mathrm{Pi}$ * SZ prevalence found in European countries. Black points indicate the places where the studies that provided the data were conducted. Areas in dark red correspond to the regions of the highest prevalence, ranging from 1:205 in Portugal (the highest in the world) to 1:300-500 in Spain, Latvia, France, and Republic of Ireland. Light red areas correspond to a prevalence range of 1:501-2,000. Dark yellow corresponds to a range of 1:2,001-2,500. Light yellow corresponds to a range of 1:2,501-5,000. Yellow green corresponds to a range of 1:5,001-25,000. Finally, medium blue and dark blue areas correspond to a range of 1:25,001-50,000 and 1:>50,000, respectively.

Interpolation maps have the important advantage of being able to provide data from regions lacking studies, based on the available data from other neighboring regions. In this regard, some of the Canary Islands closer to the coasts of Morocco appear stained with light red and yellow, suggesting that they may have a relatively high $\mathrm{SZ}$ prevalence of $\sim 1: 1,000-2,000$. Belarus, western of Ukraine, Czech Republic, Slovakia, Hungary, or Croatia appear stained in light yellow, suggesting that they may have a moderate prevalence of SZ of $\sim 1: 2,500-5,000$. The blue colors from Romania, Bulgaria, Turkey, mainland Greece, and its islands are indicative of very low prevalence (as is the case in the whole of northern Africa and the Middle East, included in this map for comparison).

\section{America, Africa, Asia, Australia, and New Zealand} Figure 2 shows a Pi*SZ prevalence IDW interpolation map of the world. Points indicate the places where the selected studies were conducted, and the 10-color scale is the same as previously described. 


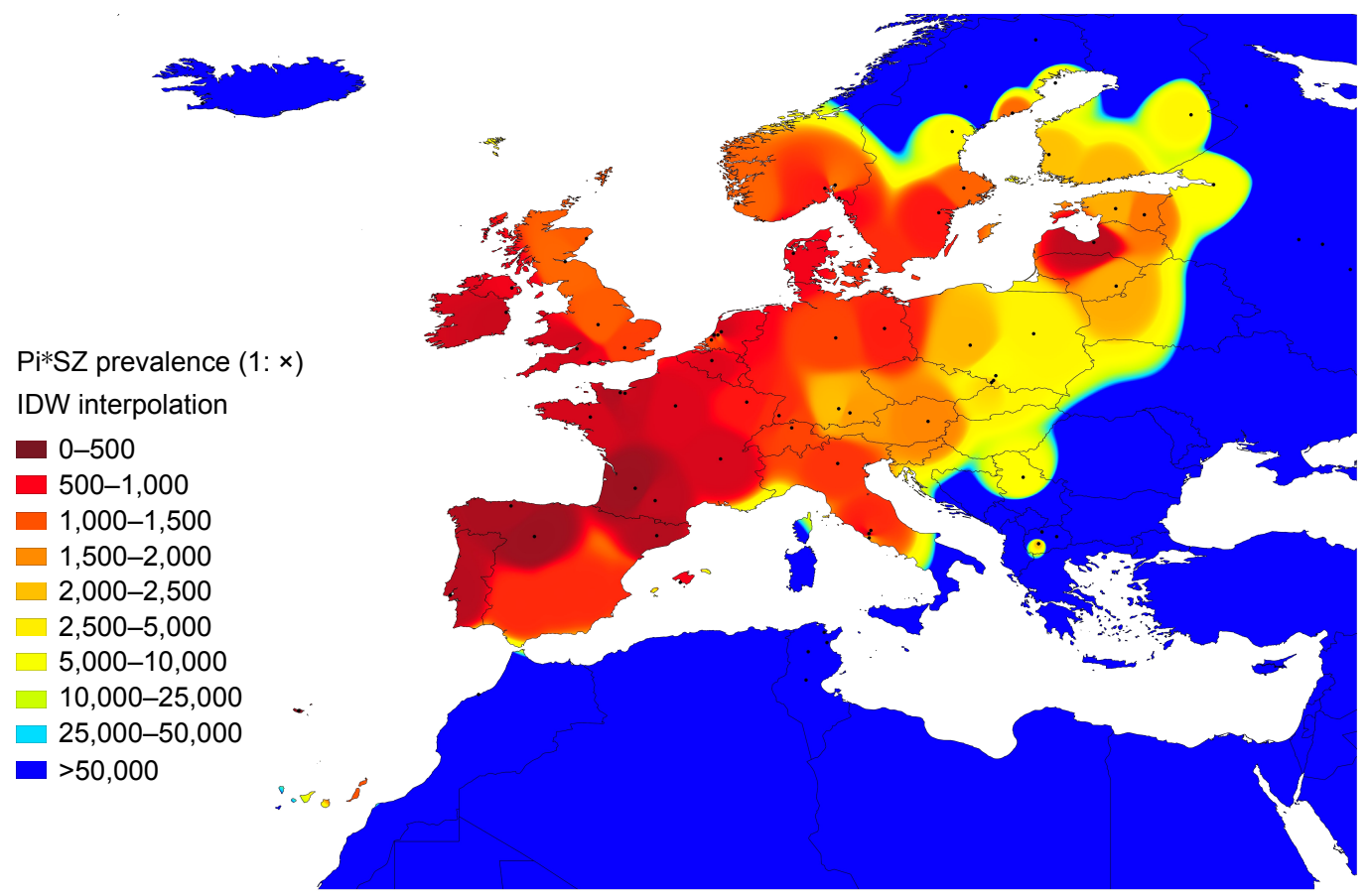

Figure I Distribution of SZ prevalence in Europe.

Notes: In this IDW interpolation map of the Pi*SZ prevalence in European countries, black points indicate the places where the studies were conducted. The areas colored in red correspond to the regions with the highest prevalence (ie, south, west, and north of Europe), those in yellow and green have moderate prevalences (eg, central Europe), and those in blue (ie, Iceland and the most extreme regions of northern, southern, and eastern Europe) are the areas with the lowest prevalences. Abbreviation: IDW, inverse distance-weighted.

Outside Europe, there are very high SZ frequencies in large areas of Canada and the USA, which appear almost totally stained in red and yellow, except in some southern states stained in medium blue, such as Georgia (with a population of African Americans, Asian Americans, Hispanics, and Latinos of $40 \%$, very close to that of the American whites).
There are also very high frequencies in the east and south of Australia, Tasmania, and throughout New Zealand.

In Central America, the Caribbean Islands, and South America, there are predominate yellow tones, indicative of a SZ intermediate mean prevalence of $\sim 1: 2,000$, with the exception of Venezuela and Brazil that have a higher

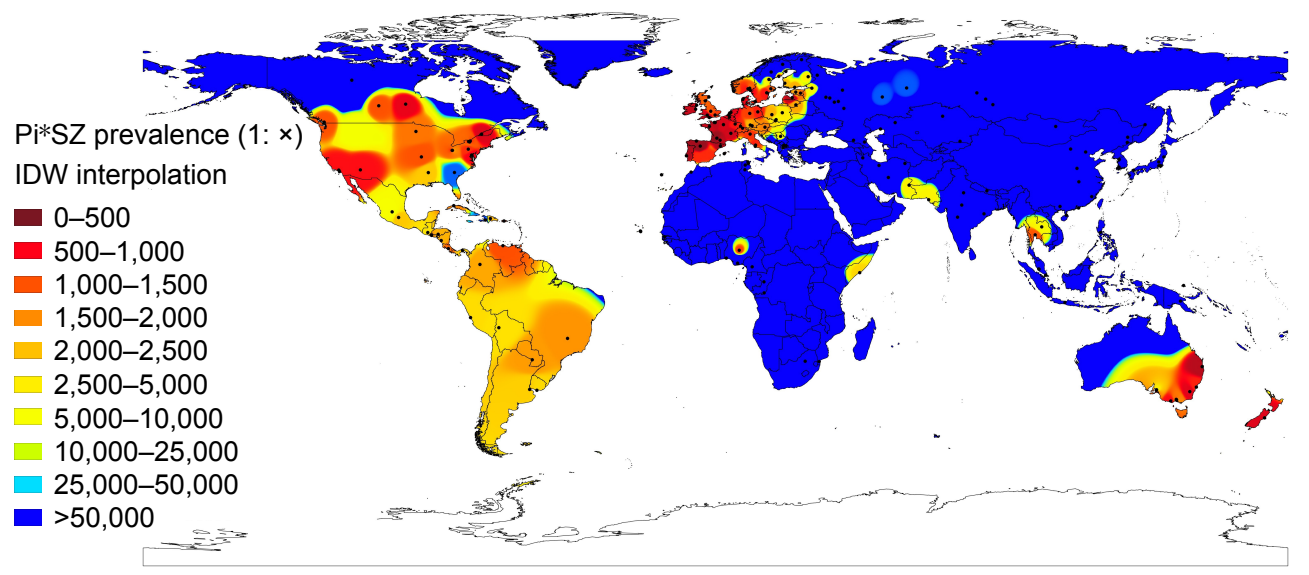

Figure 2 Distribution of SZ prevalence in the world.

Notes: In this worldwide IDW interpolation map of Pi*SZ prevalence, black points indicate the places where the studies were conducted. The red areas correspond to the regions with the highest prevalences (eg, Europe, large areas of the USA and Canada, southeast Australia, and New Zealand). Yellow areas indicate moderate prevalences (eg, Mexico, Central and South America, and isolated areas of Africa and Southeast Asia). Finally, those colored in blues (such as Africa, Asia, and extreme regions of Europe, North America, and Australia) are regions with very low or nonexistent Pi*SZ prevalence.

Abbreviation: IDW, inverse distance-weighted. 
prevalence. However, the low number of points in Central America, the Caribbean, and South America significantly reduces the reliability of these findings.

Interestingly, several coastal regions bathed by the Indian Ocean, including the Horn of Africa (Somalia), Iran, Pakistan, and Thailand, appear stained with various shades of yellow, indicating moderate or low prevalence of SZ genotypes in these areas.

In contrast, blue colors, indicative of very low or nonexistent SZ types, predominate in the Arctic regions, and in most parts of Russia, Asia, Indonesia, Africa, and northern Australia.

\section{Discussion}

The results of this analysis show that compound heterozygous SZ is relatively frequent in Caucasian subjects living in Europe, the American continent, Australia, and New Zealand. Anecdotally, low or moderate values of SZ prevalence have been found in some countries populated by non-European people from West and Northeast Africa and South Asia. However, the paucity of available studies in these countries greatly reduces the reliability of the results. Interestingly, the IDW interpolation maps detected some unexpectedly high prevalence of SZ genotypes in numerous regions around the world completely lacking in studies, such as the Canary Islands, Eastern Europe, Mexico, Central and South America, Tasmania, etc., and also showed much higher prevalence than previously thought in the USA, Canada, Australia, and New Zealand.

Summarizing the findings of this study, it could be concluded that of the 1.5 million people with SZ genotype worldwide, $48 \%$ are in southern, western, northern, and central Europe; 39\% in America (the majority in North America, Brazil, Venezuela, and Colombia); and the remaining 13\% in white individuals residing in New Zealand and Australia, and in a small number of African and Asian subjects unevenly distributed throughout Africa, and western and southern Asia.

The authors are aware that, despite having tried to make the best possible selection of studies, the estimates of this study may have biases related to the composition of the samples studied, which included newborns, blood donors, school or college students, soldiers, hospital staff, persons undergoing pre-employment or routine medical examinations, active workers, natives with specific genetic traits, a mixture of subjects generically called "healthy unrelated people," etc. Really, only a few samples from a minority of studies were representative of the general population. Another bias that may distort the results of this study is that they were necessarily based on the available data of only $37 \%$ of all the countries in the world. IDW interpolation maps were created to solve this problem, providing data to regions lacking these maps. In any case, the data estimated by IDW interpolation are much more reliable the greater the number of real data and the closer they are to one another. The points close to each other allow more precise estimates than distant points. Therefore, this technique is more reliable if the data are dense and evenly spaced. In this sense, in large regions of the world, such as South America, Africa, and large regions of Asia, not only data shortages were found but also large distances between points, which reduce the accuracy of these interpolated values. In addition, because IDW computes an average value, the value calculated for a non-sampled point can never be higher than the maximum value for a sample point or lower than the minimum value of the sample point, so this technique may be wildly inaccurate in some locations. Nevertheless, the findings of this study seem to be in accordance with the reported $\mathrm{S}$ and $\mathrm{Z}$ frequency distribution worldwide, ${ }^{12-23}$ and with the hypothesis that both deficiency alleles originate from Caucasians living in Europe at different historical times. It is believed that the $\mathrm{Pi} * \mathrm{Z}$ mutation has a relatively recent origin in Caucasians living in northern Europe $~ 2,000$ years or 66 generations ago (one generation $=30$ years), ${ }^{25}$ and it was spread into the rest of the continent through maritime and inland waterways, via Baltic countries. On the other hand, it has been proposed that the $\mathrm{S}$ variant emerged in the Iberian Peninsula 300-450 generations ago (ie, 10-15,000 years ago), and in the Franco-Cantabrian refuge area during the last glacial era, spreading from there by people who later repopulated Europe. ${ }^{26}$ Then, especially from the 16th-century AD, Europeans dispersed both genes for non-European countries to which they colonized or where they emigrated.

Since SZ genotypes express serum levels ranging from 10 to $23 \mu \mathrm{M} / \mathrm{L}$, and $20 \%$ of them express concentrations below the protective level of $11 \mu \mathrm{M}^{7}$ leading experts on the subject have estimated that $\sim 10 \%$ of SZ individuals may develop emphysema particularly if they have a history of smoking, ${ }^{27}$ and besides a possibly smaller but unknown percentage of $\mathrm{SZ}$, individuals may develop liver cirrhosis, systemic vasculitis, or panniculitis. Therefore, if these previous assumptions were true, $10 \%$ (ie, 150,000 of the 1.5 million estimated SZs in the world) would be at high risk for COPD.

Both PiZ and PiS proteins form polymers that are retained within the endoplasmic reticulum of hepatocytes causing continued cell stress, and over time cell death and repair, leading in some cases to liver damage, fibrosis, cirrhosis, 
and carcinomas, whereas the lack of circulating protein promotes the development of COPD. ${ }^{28,29}$ However, while in the $\mathrm{Z}$ mutation intracellular polymerization/retention occurs in $85 \%-90 \%$ of the molecules, in the $\mathrm{S}$ mutation polymerization occurs at most in $60 \%$ of them. ${ }^{30}$ In addition, the dramatic conformational changes of the $\mathrm{Z}$ protein determine a loss of $80 \%$ of its functional activity. In contrast, the conformational changes of the $\mathrm{S}$ protein are much less dramatic, having a normal serum half-life ${ }^{31}$ and an association rate constant for neutrophil elastase that is close to normal, retaining its inhibitory capacity unchanged. ${ }^{32}$

Interestingly, in AATD heterozygotes, the composition of their circulating AAT is inversely proportional to the amount of liver polymerization/retention of each type of AAT. For example, in a recent study, the percentage of $\mathrm{Z}$ protein in $\mathrm{MZ}$ patients was only $18 \%$ and that of $\mathrm{S}$ protein in MS patients was $37 \% .{ }^{33}$ In this regard, although the composition of serum AAT in SZ patients has not been sufficiently studied, it seems logically reasonable to accept that it could be $\sim 70 \% \mathrm{~S}$ and $30 \% \mathrm{Z}$. This would mean that some SZs with AAT levels close to the lower limit, having two-third of the circulating AAT of S-type (ie, efficient) and $1 / 3$ of Z-type (ie, poorly efficient), may be below the protective level, and therefore at increased risk for AATD-related disease development.

Pioneering researchers from Europe and the USA reported an increased risk of developing COPD in a short series of subjects with SZ phenotypes, ${ }^{34,35}$ and these results have been confirmed in subsequent studies. ${ }^{11,36}$

The data provided by some Registries of Patients with AATD have generally coincided with those findings. For example, researchers from the Spanish Registry of Patients with AATD reported the data of $348 \mathrm{Pi}^{*} \mathrm{ZZ}, 100 \mathrm{Pi} * \mathrm{SZ}$, and 21 carriers of rare deficiency variants, noting that $\mathrm{Pi}^{*} \mathrm{ZZ}$ showed more severe impairment in lung function and younger age at baseline compared with $\mathrm{Pi}{ }^{*} \mathrm{SZ}$ subjects. ${ }^{37}$ In this same way, an observational study in $547 \mathrm{ZZ}$ and $547 \mathrm{SZ}$ patients registered in the Spanish and Italian national registries showed that SZ patients were older at diagnosis and had better preserved lung function, despite a higher smoking consumption. ${ }^{38}$ Also, a comparative study between 63 PiSZ and $63 \mathrm{PiZZ}$ subjects from the UK AATD registry showed that subjects with $\mathrm{Pi}$ *SZ type showed less emphysema on CT scans, more apical predominance, less abnormal respiratory physiology test results, but similar health status impairment compared with matched subjects $\mathrm{Pi}$ ZZZ. ${ }^{39}$

The massive neonatal screening conducted by Sveger et al between 1972 and 1974 in 200,000 Swedish newborns detected 127 individuals $\mathrm{Pi}$ ZZZ and $54 \mathrm{Pi}^{*} \mathrm{SZ}$, who has been followed up regularly. ${ }^{40}$ At age 26 , SZ individuals (5\% smokers) had normal lung function test results, and a negligible percentage had marginal deviations in liver test results. ${ }^{41}$ In subsequent checkups, the lung function and quality of life of SZ patients remained quite well preserved. ${ }^{42}$

In addition, a meta-analysis performed by Dahl et al showed that pooled data from six studies found that the OR for COPD of the SZ heterozygotes was moderately but significantly increased with respect to that of the MM subjects. $^{10}$

Therefore, in the absence of definitive evidence, it is generally accepted that individuals who have the $\mathrm{Pi}$ *SZ genotype with serum AAT levels below the protective threshold value have an increased risk of developing lung disease, especially if they smoke or if they are exposed to occupational and environmental pollutants. ${ }^{6}$

The association between SZ heterozygosity and the risk of developing a chronic liver disease, panniculitis, and granulomatosis with polyangiitis is controversial, but in any case incomparably smaller than that of homozygotes ZZ. ${ }^{7}$

In conclusion, compound heterozygous SZ is relatively frequent in Caucasian subjects resident in Europe, and in their descendants residing in the American continent, Australia, and New Zealand. Since $\sim 10 \%$ of SZ individuals may develop emphysema particularly if they have a history of smoking, ${ }^{27}$ at least 150,000 of the 1.5 million estimated SZs in the world would be at high risk for COPD, and therefore, knowledge of the SZ prevalence of AATD in every community may be important for patients, physicians, and health authorities, to increase the diagnosis and to implement appropriate preventive measures.

\section{Author contributions}

This study was designed by IB, PB, and ID. IB provided the database and wrote the draft document. PB, SP-H, BL, FC, $\mathrm{CE}$, and $\mathrm{MM}$ collaborated in the redaction and revision of the manuscript. ID designed the IDW figures summarizing the database. All authors contributed toward data analysis, drafting and revising the paper, gave final approval of the version to be published, and agree to be accountable for all aspects of the work.

\section{Disclosure}

The authors report no conflicts of interest in this work.

\section{References}

1. de Serres F, Blanco I. Role of alpha-1 antitrypsin in human health and disease. J Intern Med. 2014;276:311-335. 
2. Long GL, Chandra T, Woo SLC, Davie EW, Kurachi K. Complete sequence of the cDNA for human alpha-1-antitrypsin and the gene for the S variant. Biochemistry. 1984;23:4828-4837.

3. Brantly M, Nukiwa T, Crystal RG. Molecular basis of alpha-1antitrypsin deficiency. Am J Med. 1988;84:13-31.

4. Cox DW, Johnson AM, Fagerhol M. Report of nomenclature meeting for alpha-1 antitrypsin. Hum Genet. 1980;53:429-433.

5. Lomas DA, Mahadeva R. Alpha1-antitrypsin polymerization and the serpinopathies: pathobiology and prospects for therapy. J Clin Invest 2002;110:1585-1590.

6. American Thoracic Society/European Respiratory Society Statement: standards for the diagnosis and management of individuals with alpha1-antitrypsin deficiency. Am J Respir Crit Care Med. 2003; 168:818-900.

7. Stoller JK, Lacbawan FL, Aboussouan LS. Alpha-1 antitrypsin deficiency. In: Pagon RA, Adam MP, Ardinger HH, Wallace SE, Amemiya A, Bean LJH, Bird TD, Ledbetter N, Mefford HC, Smith RJH, Stephens K, editors. GeneReviews ${ }^{\circledR}$ [Internet]. Seattle (WA): University of Washington, Seattle; 1993-2017 [updated January 19, 2017].

8. Brantly ML, Paul LD, Miller BH, Falk RT, Wu M, Crystal RG. Clinical features and history of the destructive lung disease associated with alpha-1-antitrypsin deficiency of adults with pulmonary symptoms. Am Rev Respir Dis. 1988;138:327-336.

9. Brantly ML, Wittes JT, VogelmeierCF,Hubbard RC, Fells GA, CrystalRG Use of a highly purified alpha 1-antitrypsin standard to establish ranges for the common normal and deficient alpha 1-antitrypsin phenotypes. Chest. 1991;100:703-708.

10. Dahl M, Hersh CP, Ly NP, Berkey CS, Silverman EK, Nordestgaard BG. The protease inhibitor PI*S allele and COPD: a meta-analysis. Eur Respir J. 2005;26:67-76.

11. Turino GM, Barker AF, Brantly ML, et al. Clinical features of individuals with $\mathrm{PI}$ SZ phenotype of alpha 1-antitrypsin deficiency. alpha 1-Antitrypsin Deficiency Registry Study Group. Am J Respir Crit Care Med. 1996;154:1718-1725.

12. Blanco I, Bueno P, Diego I, et al. Alpha-1 antitrypsin Pi*Z gene frequency and $\mathrm{Pi}$ *ZZ genotype numbers worldwide: an update. Int $J$ Chron Obstruct Pulmon Dis. 2017;12:561-569.

13. Hutchison DC. Alpha 1-antitrypsin deficiency in Europe: geographical distribution of Pi types S and Z. Respir Med. 1998;92:367-377.

14. Blanco I, E Fernández, EF Bustillo. Alpha-1-antitrypsin PI phenotypes $\mathrm{S}$ and $\mathrm{Z}$ in Europe: an analysis of the published surveys. Clin Genet. 2001;60:31-41.

15. Blanco I, EF Bustillo, MC Rodríguez. Distribution of a1-antitrypsin PI $\mathrm{S}$ and PI Z frequencies in countries outside Europe: a meta-analysis. Clin Genet. 2001;60:431-444.

16. Miravitlles M. Alpha1-antitrypsin deficiency: epidemiology and incidence. Respir Med. 2002;96:205.

17. de Serres FJ. Worldwide racial and ethnic distribution of alpha1antitrypsin deficiency: summary of an analysis of published genetic epidemiologic surveys. Chest. 2002;122:1818-1829.

18. de Serres FJ, Blanco I, Fernández-Bustillo E. Ethnic differences in alpha-1 antitrypsin deficiency in the United States of America. Ther Adv Respir Dis. 2010;42:63-70.

19. de Serres FJ, Blanco I, Fernández-Bustillo E. Health implications of alpha1-antitrypsin deficiency in Sub-Sahara African countries and their emigrants in Europe and the New World. Genet Med. 2005; 7:175-184.

20. Blanco I, de Serres FJ, Fernandez-Bustillo E, Lara B, Miravitlles M. Estimated numbers and prevalence of PI*S and PI*Z alleles of alpha1-antitrypsin deficiency in European countries. Eur Respir J. 2006;27:77-84.

21. de Serres FJ, Blanco I, Fernández-Bustillo E. Estimated numbers and prevalence of $\mathrm{PI} * \mathrm{~S}$ and $\mathrm{PI} * \mathrm{Z}$ deficiency alleles of alpha1-antitrypsin deficiency in Asia. Eur Respir J. 2006;28:1091-1099.

22. de Serres FJ, Blanco I. Prevalence of $\alpha 1$-antitrypsin deficiency alleles $\mathrm{PI}^{*} \mathrm{~S}$ and $\mathrm{PI}{ }^{*} \mathrm{Z}$ worldwide and effective screening for each of the five phenotypic classes PI*MS, PI*MZ, PI*SS, PI*SZ, and PI*ZZ: a comprehensive review. Ther Adv Respir Dis. 2012;6:277-295.
23. Blanco I, de Serres FJ, Cárcaba V, Lara B, Fernández-Bustillo E Alpha-1 antitrypsin deficiency $\mathrm{PI} * \mathrm{Z}$ and $\mathrm{PI}{ }^{*} \mathrm{~S}$ gene frequency distribution using on maps of the world by an inverse distance weighting (IDW) multivariate interpolation method. Hepat Mon. 2012;12(10 HCC): e7434.24.

24. Lu GY, Wong DW. An adaptive inverse-distance weighting spatial interpolation technique. Comput Geosci. 2008;34:1044-1055.

25. Lace B, Sveger T, Krams A, Cernevska G, Krumina A. Age of SERPINA1 gene PI Z mutation: Swedish and Latvian population analysis. Ann Hum Genet. 2008;72:300-304.

26. Luisetti M, Seersholm N. Alpha1-antitrypsin deficiency. 1: epidemiology of alpha1-antitrypsin deficiency. Thorax. 2004;59:164-169.

27. McElvany N, Crystal RG. Clinical manifestations of $\alpha_{1}$ AT deficiency. In: Crystal RG, editor. Alphal-antitrypsin deficiency. New York: Marcel Dekker; 1996:227-243.

28. Lomas DA, Evans DL, Finch JT, Carrell RW. The mechanism of Z alpha 1-antitrypsin accumulation in the liver. Nature. 1992; $357: 605-607$.

29. Teckman JH. Liver disease in alpha-1 antitrypsin deficiency: current understanding and future therapy. COPD. 2013;10(Suppl 1):35-43.

30. Elliott PR, Stein PE, Bilton D, Carrell RW, Lomas DA. Structural explanation for the dysfunction of $\mathrm{S} \alpha 1$-antitrypsin. Nat Struct Biol. 1996;3:910-911.

31. Jeppsson JO, Laurel CB, Nosslin B, Cox DW. Catabolic rate of alpha1antitrypsin of Pi types S, and MMalton and of asialylated M-protein in man. Clin Sci Mol Med. 1978;55:103-107.

32. Ogushi F, Hubbard RC, Fells GA, et al. Evaluation of the S-type of alpha-1-antitrypsin as an in vivo and in vitro inhibitor of neutrophil elastase. Am Rev Respir Dis. 1988;137:364-370.

33. Donato LJ, Karras RM, Katzmann JA, Murray DL, Snyder MR. Quantitation of circulating wild-type alpha-1-antitrypsin in heterozygous carriers of the S and Z deficiency alleles. Respir Res. 2015;16:96.

34. Larsson C, Dirksen H, Sundström G, Eriksson S. Lung function studies in asymptomatic individuals with moderately (Pi SZ) and severely (Pi Z) reduced levels of alpha1-antitrypsin. Scand J Respir Dis. 1976;57:267-280.

35. Gadek JE, Crystal RG. $\alpha 1$-antitrypsin deficiency. In: Stansbury JB, Wyngaardon JB, Frederickson DS, Goldstein JI, Brown MS, editors. The metabolic basis of inherited disease. 5th ed. New York: McGrawHill; 1982:450-467.

36. Hutchison DC, Tobin MJ, Cook PJ. Alpha 1 antitrypsin deficiency: clinical and physiological features in heterozygotes of Pi type SZ. A survey by the British Thoracic Association. Br J Dis Chest. 1983; 77:28-34.

37. Lara B, Miravitlles M. Spanish registry of patients with alpha-1 antitrypsin deficiency; comparison of the characteristics of PISZ and PIZZ individuals. COPD. 2015;12(Suppl 1):27-31.

38. Piras B, Ferrarotti I, Lara B, et al. Clinical phenotypes of Italian and Spanish patients with $\alpha 1$-antitrypsin deficiency. Eur Respir J. 2013;42:54-64.

39. Holme JL, Stockley RA. CT scan appearance, densitometry, and health status in protease inhibitor SZ alpha1-antitrypsin deficiency. Chest. 2009;136:1284-1290.

40. Sveger T. Liver disease in alpha1-antitrypsin deficiency detected by screening of 200,000 infants. N Engl J Med. 1976;294:1316-1321.

41. Piitulainen E, Carlson J, Ohlsson K, Sveger T. Alpha1-antitrypsin deficiency in 26-year-old subjects: lung, liver, and protease/protease inhibitor studies. Chest. 2005;128:2076-2081.

42. Tanash HA, Nystedt-Düzakin M, Montero LC, Sveger T, Piitulainen E. The Swedish $\alpha 1$-antitrypsin screening study: health status and lung and liver function at age 34. Ann Am Thorac Soc. 2015;12:807-812. 


\section{Publish your work in this journal}

The International Journal of COPD is an international, peer-reviewed journal of therapeutics and pharmacology focusing on concise rapid reporting of clinical studies and reviews in COPD. Special focus is given to the pathophysiological processes underlying the disease, intervention programs, patient focused education, and self management protocols.

This journal is indexed on PubMed Central, MedLine and CAS. The manuscript management system is completely online and includes a very quick and fair peer-review system, which is all easy to use. Visit http://www.dovepress.com/testimonials.php to read real quotes from published authors.

Submit your manuscript here: http://www.dovepress.com/international-journal-of-chronic-obstructive-pulmonary-disease-journal 